\title{
A FÍSICA COMO COMPONENTE CURRICULAR NOS CURSOS DE LICENCIATURA EM MATEMÁTICA DO IFSP
}

\author{
Natanael Antônio Arantes de Paula ${ }^{1}$ \\ Leandro Salmagi Coutinho ${ }^{2}$ \\ Paulo Roberto Barbosa ${ }^{3}$
}

Resumo: A prática pedagógica na educação matemática demanda a contextualização dos modelos matemáticos em situações cotidianas do aluno, e na inter-relação com outras áreas do conhecimento, de modo que instituições de ensino têm se esforçado em complementar o currículo de licenciaturas em matemática com disciplinas de áreas correlatas, em especial, a física. Neste trabalho, foram analisados os programas e currículos de cursos de licenciatura em matemática dos diversos campi do Instituto Federal do Estado de São Paulo, e outras instituições de ensino público e privado, com o objetivo de contribuir com uma discussão sobre o papel da física nos cursos de Licenciatura em Matemática do Instituto Federal de São Paulo - IFSP. Uma sistematização dos conteúdos e temas de física mais abordados é apresentada. Esta pesquisa contribui como subsídio para discussões futuras sobre o papel da física nos cursos de Licenciatura em Matemática.

Palavras-chave: Educação; Licenciatura; Matemática; Física; Currículo.

\footnotetext{
${ }^{1}$ Licenciando em Matemática, Instituto Federal de São Paulo, Campus São José dos Campos, Brasil. E-mail: depaulanatan@gmail.com.

2 Co-orientador, Professor de Física, Instituto Federal de São Paulo, Campus São José dos Campos, Brasil. Email: salmagi@ifsp.edu.br.

${ }^{3}$ Orientador, Professor de Matemática, Instituto Federal de São Paulo, Campus São José dos Campos, Brasil. Email: paulorb@ifsp.edu.br.
} 